\title{
Book Design Program: a Transition to a Hybrid Publishing Context
}

\author{
Ana Catarina SILVA ${ }^{\mathrm{a}, 1}$ and Maria Manuel BORGES ${ }^{\mathrm{b}}$ \\ ${ }^{a}$ CETAC. Media, Universidade do Porto, Portugal \\ ${ }^{b}$ CETAC. Media, Universidade de Coimbra, Portugal
}

\begin{abstract}
This study is developed within the scientific areas of Information Science, Communication Sciences and Editorial Design. It refers to the hybrid publishing context in which there is a coexistence of electronic and print processes, and to the role played by Information and Communication Technologies. This scenario is conditioned by technical, morphological and cultural transformations, in the words of Roger Chartier, and represents a singular moment to observe the book and its construction processes, valuing it in its various embodiments and contexts. Considering this, the present study sought to contribute to an adaptation of the methodological tools; and an optimization of the designer's communication and information flow. In order to achieve these goals we defined two main tasks: (i) comparative analysis of traditional publishing and hybrid publishing, (ii) characterization of the designer's communication and information flows that exist in the context of hybrid publishing. To do so, we adopted qualitative research methods, with literature review and content analysis. This procedure allowed us to conclude that the publishing industry is making major investments (in what concerns organization and capital) in implementing hybrid publishing schemes. Nevertheless, there is still a lack of adequacy of design programs in this scenario. This adaptation involves a redirection of the focus of the design program, not to controlling the final shape of the object (book), but to regulating it. This procedure can only be possible with a dynamic information flow in which the editorial subject is flexible and built inside a participatory scheme by the various agents.
\end{abstract}

Keywords. Hybrid publishing; printed book, e-book, editorial design.

\section{Introduction}

Recent technological developments have facilitated the emergence of a new order of communication. This changes the way we see the book today. The dynamic, decentralized and interactive modes of reading introduce alternative forms of communication and some properties of the printed book (such as the extension of memory, its intertextuality, accessibility and functionality) are enhanced in the new electronic reading devices. Others are constrained.

Roger Chartier [10] believes that this "revolution" is now the most radical to date, since it presents changes that, for the first time, occur simultaneously:

${ }^{1}$ Corresponding Author: Ana Catarina Silva, CETAC.MEDIA - Centro de Estudos das Tecnologias e Ciências da Comunicação, Praça Coronel Pacheco, 8 , 4045-453 Porto, Portugal; Email: anavieirasilva@gmail.com. 
La conséquence de tout cela est de penser que la radicale nouveauté du temps contemporain est le fait que c'est dans la même période de temps que se lient les unes aux autres les révolutions techniques, morphologiques et culturelles qui autrefois n'étaient pas liées les unes aux autres.

For all these reasons, we witness a mutation in the dominance of the printed word as a foundation of culture. Its status is now under discussion, as in several episodes of history.

The matrix of thought is that of "typographic man" and as such the application of principles that refer to print is inevitable, now that new writing and reading technology of digital nature arise. But we also recognize the need to think about new solutions that leverage the electronic format of the new book and publishing processes. It is therefore necessary to consider the specifics of the book, in both its print and electronic nature. The designer must be fully aware of the operational and symbolic potential of the book, without forgetting its heritage as a founder of civilization and the establishment of the modern human. This opens a huge field of theoretical and practical reflection on the processes of communication and information flows associated with the book, in which design plays an important role.

This study has its basis in the scientific field of Information and Communication Sciences and Editorial Design, and refers to the design of the book in a hybrid editorial context. Its relevance stems from empirical verification that the publishing market requires more flexible and interchangeable designs, which, in turn, require different design programs. This means that not only the content but also the structure and morphology of the book are now widely discussed in the traditional circuits and new media [22].

The hybrid editorial context we refer to fits within the universe of the printed book (with traditional publication processes), and the universe of e-book (aimed at electronic reading devices). It concerns the editorial processes that, at times, may alter the direction of its flow and adapt to different modes of production (such as offset or digital) or result in final objects of different natures (such as printed or electronic). For all these reasons, we find this the perfect timing to think about the book and its construction processes, perceiving and appreciating it in its various materializations and contexts, whether printed or electronic.

\section{Scope and Methodology}

The aim of this study is to contribute to an adaptation of the methodological tools; and an optimization of the designer's communication and information flow. In order to achieve these goals we defined two main tasks for this study: (i) comparative analysis of traditional publishing and hybrid publishing, (ii) characterization of the designer's communication and information flows that exist in the context of hybrid publishing. To do so, we adopted qualitative research methods, with literature review and content analysis. The study of written sources was based in the insights of some prominent authors in the field of book history such as Henry-Jean Martin, Lucien Febvre [14], Robert Darnton [12], Roger Chartier [9,10], in authors who address the mediation and the digital future of the book, as Alistair McCleery and David Finkelstein [16], Bill Cope and Angus Phillips [11], N. Katherine Hayles [21], Johanna Drucker [13], Sven 
Birkerts [5] and Jay David Bolter [7, 8], and authors that explore the context of hybrid publishing as José Afonso Furtado [17, 18, 19, 20] and John B. Thompson [29].

\section{The Transition to a Hybrid Context}

The digital mediation essentially altered the order of books to the extent of the production, distribution and reading of the book, more than the book in itself. The introduction of new information and communication technologies in publishing contexts implies a new literacy, but also an organizational paradigm shift. The tasks inside a book production workflow change and the outcome is less definitive and increasingly divided, within a cross-media publishing logic.

The digital processes allow a product diversification, without incurring a replacement of old by new. From this stems a hybrid publishing scenario that definitively ends the fundaments of the dichotomy printed book / e-book, something that we can see graphically represented in the Adoni and Nossek model [1].

This is a dialectical model of media interactions that presents three possible scenarios: functional equivalence, functional differentiation and functional multiplicity. The first leads to a substitution of one media for the other. The second allows the coexistence of both. The third represents the synthesis of two media, resulting in a new media.

The hybrid publishing context we refer to, depending on the degree of functional differentiation of the editorial products (printed book, e-book, multimedia product, etc.), is illustrated at the bottom of the diagram (co-existence, interchangeability). Both the traditional (printed) and the new forms originating from digital fit there.

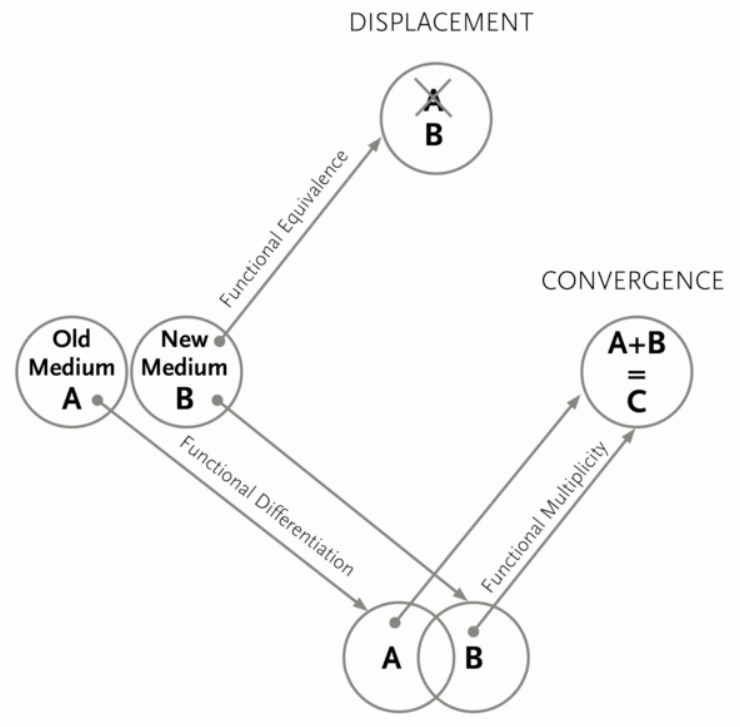

CO-EXISTENCE/INTERCHANGEABILITY

Figure 1. Dialectical model of media interactions [1]. 
The present and future of the book, in its various forms, is therefore based on this differentiation factor. For this reason, we can say with certainty that the predictions of the death of the book are at least exaggerated:

...the persistence of reading books might be related to the degree of interchangeability or uniqueness of print media use. If reading books fulfills psycho-social needs for the individual reader, then it can be assumed that it will persist as a cultural behavior even in the multi-media environment [1].

We find that the current publishing context isn't based on a fundamental change of the object (from print to electronic, for example), but rather on its repositioning. If before the digital revolution the book was the epitome of content and its representation, while its entire value chain was largely based on its materiality, storage and distribution, currently the impact of new technologies has led to greater awareness of the intangible nature the contents of books. Today books, before being books, they are digital content. They are "information architecture" [11].

The digital assets become publishers' main raw material in this digital revolution. And the head function of these agents becomes the Digital Content Management, or DCM.

The distribution across multiple platforms, or cross-media publishing, implies a flexible reuse of content and its publication through different channels and in different media, digital or printed. For this, we must develop appropriate workflows, a true digital workflow that includes DCM tools.

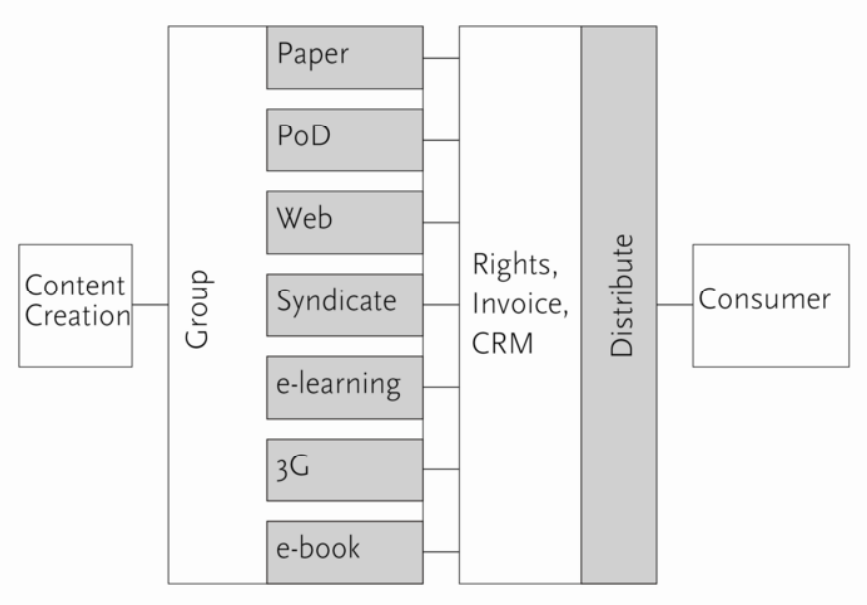

Figure 2. Cross-media publishing [20].

The adoption of a digital workflow is an ongoing process within many industries in the publishing universe. Organizational practices, work and capital flows in the publishing industry are changing, but until it doesn't reconvert, we will see a certain precariousness in the quality of hybrid publishing, as digital files are used in the manufacture of books with different natures (print and electronic), without taking into account their specificities. 
Fig.3 presents a digital workflow, as Thompson [29] sees it. We can see that this scheme is planned to have a particularization of the final output, with respect to the production of the book. In the last phase of the scheme proposed by Thompson, we can see that there is a planned conversion of the digital file that originally serves print, to an electronic output, i.e., the e-book, in its different formats (when this scheme was published). Yet it is curious that there is a "conversion." This means that digital assets are still designed for one particular output, only there is the possibility to adapt them to another.

What we believe to be a true digital workflow is somewhat different, in that it includes another mode of production, in which the digital content has no fixed form. Instead, it takes form in an appropriate manner to each of the different distribution channels, as illustrated in Fig.4.

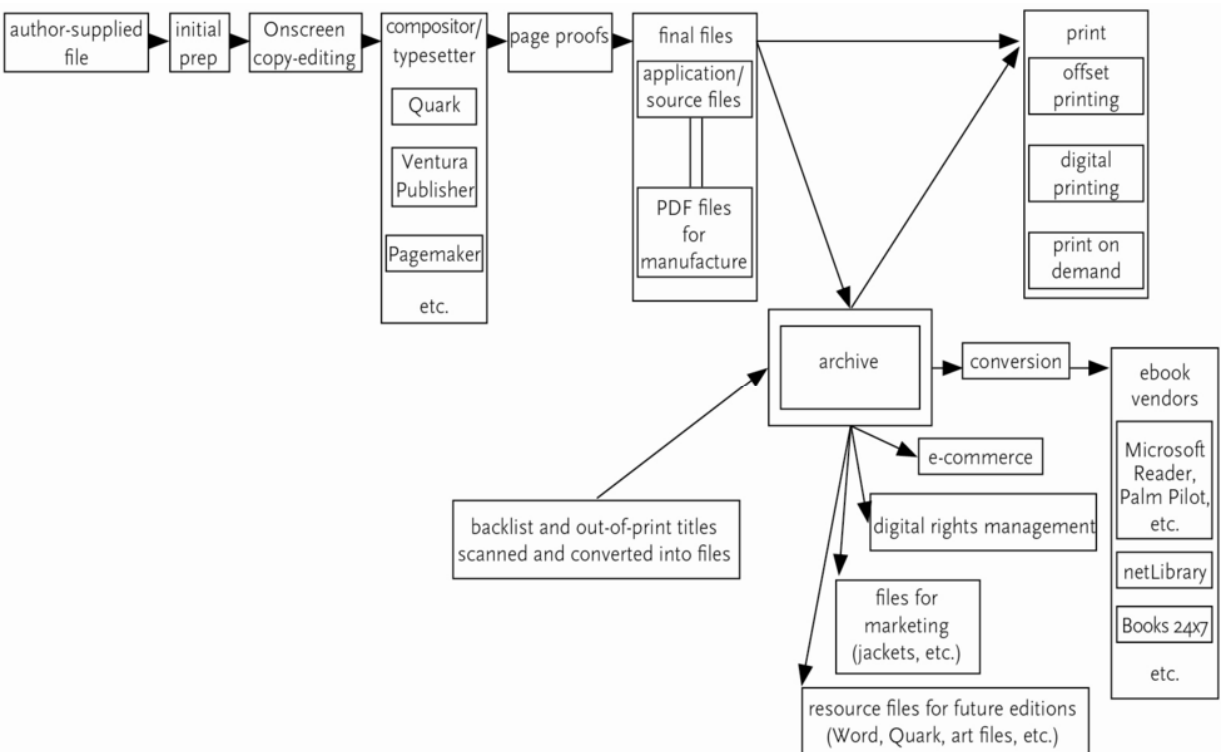

Figure 3. Digital workflow [29].

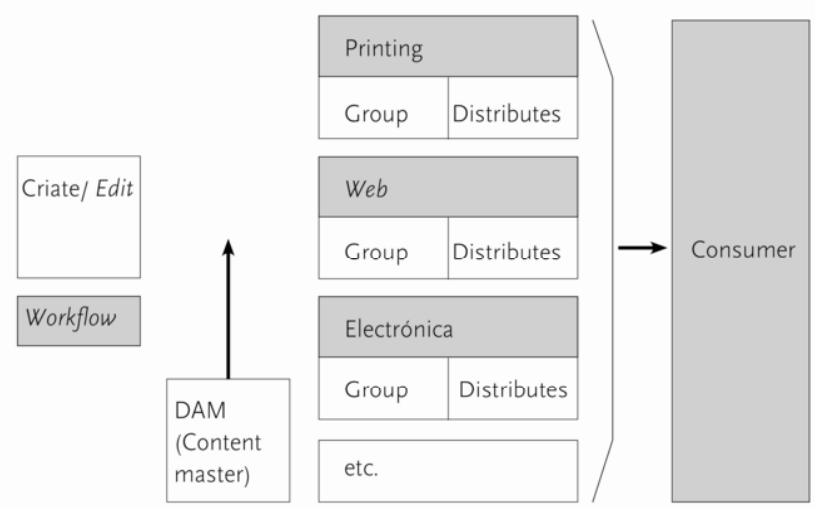

Figure 4. Repurposing workflow [20]. 
This new framework also enables some significant changes in reading and in its processes. And the main result of the digital revolution, with regard to the book is the definitive transition from what Roger Chartier calls a system of intensive reading to that of extensive reading, a process that begins with the printed book (and its mass distribution). Maria Augusta Babo [3] referring to the concepts of Chartier, defines the first regime (intensive reading) as recurrent and meditative, and the second (extensive reading) as comprehensive and informative. Now, these modalities have been heightened in two types of reading, known as "speed reading" and "deep reading." But inside this new regime of extensive reading, if not radicalized, we can also recognize some insights of Edgar Morin, about the complexity and different ways of thinking the real, not through a set of unconnected simple units of knowledge, but as a result of their relationship and interconnection. Only this way can we devise an appropriate way of reading, suited to the new requirements and incentives of a "plurisemiotic" [4] and intertextual regime in which we live today. Babo [4], in reference to Bertrand Gervais, describes this scenario in which the text spreads through the media, complemented with images, in different embodiments, hipertextualizing, leading to an accelerated and diversified reading.

The concept of hypertext is, precisely, one of the major reasons for the change in the ways of reading, as we move from mechanical to digital. "Hypertext" is a term introduced by Theodor Nelson in 1965 that defines a non-sequential writing, in which the player choses the links.

Reading in a digital environment therefore requires different ways of reading and a transformation in the appearance of the text, considering its different operationality. The e-book is one support that enables this. And a new problem emerges: the book, that established unity, with five centuries of history, is once again undefined. The digital technology mediated book must recreate the codex functionalities, something that in the last decades has been mistaken for a formal recreation, by many book agents, and in particular, by the designer.

The dream of the electronic distribution of content has led to many experiences since the late eighties of the twentieth century. But it was the internet (and not the floppy-disk or CD-ROM) that paved the way for the digital publishing revolution we live in today. Thompson [29] lists four reasons for the initial limited success of the ebook: (1) hardware, (2) formats, (3) rights, (4) price. Nowadays, within these parameters, an e-book already has technical, industrial and trading features that take it to overcome these hurdles. But as Johanna Drucker [13] identifies, the conceptual obstacles remain: "Functions are not the same as formal features". And the author highlights the phenomenon of the e-book emulating the codex. Drucker, referring IBM's researcher Harold Henke, questions the relevance of the "metaphors" of book structure, attempts to seduce the reader with familiar features from print.

Reproductions of: page volume, turn of the page, sound of flipping, spine of the book (referring to the double page spread when it really comes to a single page that is the screen), among other effects have, in Drucker's point of view, an opposite result: "I would argue that as long as visual cues suggest a literal book, our expectations continue to be constrained by the idea that books are communication devices whose form has a static and formal, rather than active and functional, origin".

Drucker suggests another approach to the book: rather than working as a formal structure, the book should be made from its program which in turn comes from the needs that the formal structure of the book presents. 


\section{Book Design Program}

The definition of the design program of a book is born in the dialogue (direct or otherwise) of the designer with the publisher and the author. It involves an analysis of the contents and comes from the identification of all the requirements and constraints. Drucker describes her approach as follows: (i) analyze "how" the book "works" and not describe what the book "is", (ii) determine the "program" that comes from the formal structures of the book, (iii) discard any iconic "metaphor" of book structure, focusing on understanding how these forms regulate the performance of the book itself. From here, the literal space ${ }^{2}$ of the book becomes a space of intervention for the reader. Bill Cope and Angus Phillips [11] also argue that a new definition of what the book is should be focused on function rather than the object: "A book is not a thing. It is a textual form, a way of communicating. A book is not a product. It is an information architecture" [11] But emphasize the intrinsic characteristic of any book, which is its "bookish" structure: "A book is no longer a physical thing. A book is what a book does" [11].

A book, recognizable in the world of books, presents some general characteristics such as: the fact that it is an extensive text (by "text" we refer to text and/ or images), being organized by some paratexts as covers, production notes; title, author, copyright, ISBN, or DOI (Digital Object Identifier) table of contents, headings, subheadings and body text, indexes, acknowledgments, foreword, author's biography, introduction, among others.

In summary, this is how the authors [11] identify what the book "does": presents a characteristic textual or communicative structure, and features the typical functions of "books", because it is defined, registered and recognized as a book.

This concept of information architecture is also present in the insights of Craig Mod [26] about the future of the book. He understands it stems from relationships and not from a (metaphorical and literal) surface. He states that the books are systems: "They emerge from systems. They themselves are systems - the best of which are as complex as necessary and not a bit more. And once complete, new systems develop around their content."

Electronic text, distributed online, accessed through a computer, smart-phone, tablet, or dedicated reader, brings a new variable to this equation that is the hybrid publishing process. That workflow, only addressed to print, must now be a hybrid one, so that the final product can either be the printed book or the e-book. Both have the same origin in a digital file, although the way this digital information is mediated by the different stakeholders in the chain of production of the book conditions the book and its use.

At this point it also has to be considered the relationships between technologies, markets and types of content [20]. Because the publishing industry is very diverse, it appears that the digital revolution also has a different impact on the various sectors of the publishing universe. One can understand why some book categories (like encyclopedias, for example) have adopted hybrid forms so quickly, if not migrated to electronic form, while others hold to the paper.

\footnotetext{
${ }^{2}$ Drucker defines the literal book, "that familiar icon of bound pages in finite, fixed sequence" and contrasts it with the phenomenal book, "the complex production of meaning and effect that arises from dynamic interaction with the literal work."
} 


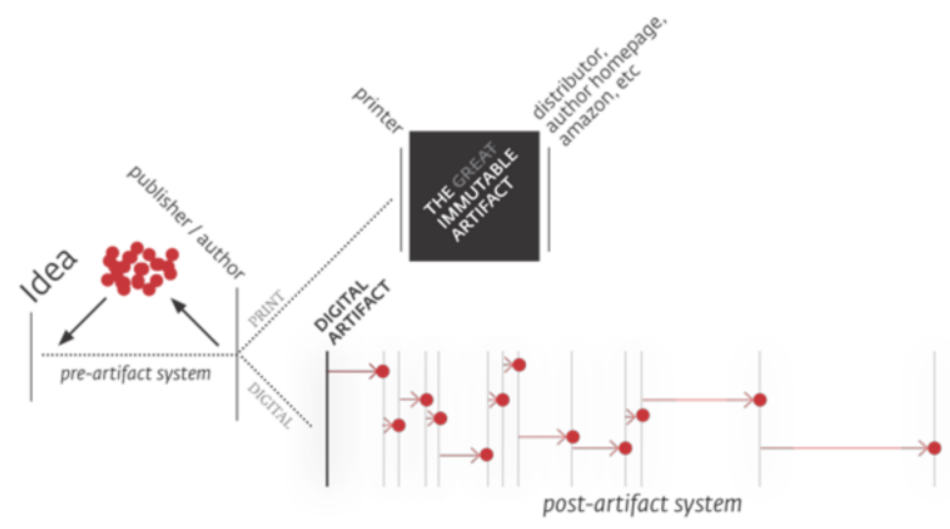

Figure 5. A ridiculously simplified diagram of how digital affects book publishing [26].

The fact that digital media have come to add great possibilities to the methods already confirmed by history and part of the modern way to access and read information is now unavoidable. For this reason it is necessary to rethink the processes and relationships between the various actors so that the shape of the final book, whether printed or electronic, is potentiating of its content. In the present study we seek to do so from the point of view of one player in particular: the designer.

Design is what makes "the Beautiful, the Good and Useful" possible, wrote Giambattista Bodoni ${ }^{3}$ in 1818 [6]. It is also the process that leads to the operation of a projectual methodology that determines the solution of a problem or as Bruno Munari [27] puts it, a series of operations, arranged in a logical order dictated by experience.

Within the disciplines of graphic design, editorial design is perhaps the one that remained the most faithful to the functional ideals of the origins of design. Not only because it was after the book (and printing) that a theoretical corpus first started to take form, but also, because this object, in its modern configuration of codex has remained largely unchanged for five centuries, such was the degree of optimal functionality and aesthetic reached. Today, with the introduction of digital processes, this form is not compromised, but the design program is, as Hayles [21] states:

So essential is digitality to contemporary processes of composition, storage, and production that print should properly be considered a particular form of output for digital files rather than a medium separate from digital instantiation. The digital leaves its mark on print in new capabilities for innovative typography, new aesthetics for book design, and in the near future new modes of marketing.

\footnotetext{
${ }^{3}$ In his work of 1818 [6], Bodoni establishes a set of rules to build a good book. Some of which were more scientific, others more empirical. His analysis begins by distinguishing three aspects "the Beautiful, the Good and the Util." The utility is measured in how many people are lured into reading, the number of readings, the pleasure of reading and the speed of reading. A good book is one that motivates most from this. As for the beautiful, it consists of two things: "harmony which satisfies the spirit by enabling it to recognize that all individual parts of a work are subordinated to a complete idea; it also consists of proportions which please the eye or rather the imagination, for the imagination contains within itself certain definite ideas or images, and the more that which is perceived coincides with them, the greater the pleasure one takes in it."
} 
The physical characteristics of the book as the texture, smell, weight, size, proportion, light, color are significant and contribute to an experience of the book as cultural text. But the text, seen as a set of words inscribed on the pages (printed or digital) of a book should also be clarified in terms of its operationality. Thus, the effectiveness of communication is influenced by dimensions such as readability and intelligibility, but also depends largely on design issues that are based on typography, layout and text body. The mold that regulates its meaning.

This relationship, with respect to the electronic environment, is now problematic. Not only did the graphic design has been unable to adapt to new demands of the environment, but also the interfaces and platforms need to become accessible, including principles of user-centered design. In 2009, a report of the Joint Information Systems Committee (JISC) [23], found that "they are far from ideal, and in some cases, barely serviceable." Today the scenario is still undefined: "What's happening at the moment is that most publishers are handing their major titles over to app developers who are ruining these titles with rushed, unprofessional layout and design. (...) The complete lack of care and attention paid to the production of digital books is genuinely mystifying" [24].

Defining the future of digital media, and particularly the e-book, is a difficult task. However, there are key concepts in the interaction design field that can be a reference. In the french committee's report on the e-book Bruno Patino [28] lists some that can help improve in creating new uses and experiences: mobility, interoperability, access, connection, interactivity, information optimization.

Now graphic design will have to find the tools to enable the best experience of the book, both as printed and as e-book. This will be possible through dynamic information flows, acknowledging the book as an information architecture [11] and not as a fixed and unchanging structure.

\section{Next Chapters}

In this scenario of digital revolution the "professions of the book" have been changing. Namely the designer who is required a greater versatility. The publishing industry is now making major investments (both organizational and capital) in order to implement hybrid publishing workflows. However, this study pointed us that there is still a lack of adequacy of design programs to this scenario. This adaptation demands a refocusing of the design program, not to the control of the final shape of the object (book), but towards its regulation. This way of acting must be based on dynamic information flows, in which the editorial subject is flexible and built in a participatory way by various agents.

\section{References}

[1] ADONI, Hanna; NOSSEK, Hillel, The New Media Consumers: Media Convergence and the Displacement Effect. Communication \& Medicine, Volume 26 (1), (2001)

[2] BABO, Maria Augusta, A Escrita do Livro, Vega, Lisboa, 1993.

[3] BABO, Maria Augusta, Os desafios do hipertexto, 2005, http://www.interact.com.pt/memory/12/html/interact12_10.htm 
[4] BABO, Maria Augusta, Do texto como textura heterogénea ao texto como textura híbrida, 2005, http://bocc.ubi.pt/pag/babo-maria-augusta-texto-como-textura-heterogenea-texto-como-texturahibrida.pdf

[5] BIRKERTS, Sven, The Gutenberg Elegies: the Fate of Reading in an Electronic Age, Faber and Faber, New York, 2006.

[6] BODONI, Giambattista, Manuale Tipografico 1818. In FÜSSEL, Stephan (ed.), Manual of Tupography, Taschen, Köln, 2010.

[7] BOLTER, Jay David, Remediation: Understanding New Media, The MIT Press, Cambridge, 2000.

[8] BOLTER, Jay David, Writing Space: Computers, Hypertext, and the Remediation of Print. Routledge, New York, 2001.

[9] CHARTIER, Roger, A ordem dos livros, Vega, Lisboa, 1997.

[10] CHARTIER, Roger Roger Chartier, Interview by Eric Ouzounian. October 10, 2010. December 10, 2011. http://www.laspirale.org/texte.php?id=311

[11] COPE, Bill; PHILLIPS, Angus (Eds.), The Future of the Book in the Digital Age, Chandos Publishing, Oxford, 2006.

[12] DARNTON, Robert, The Case for Books: Past, Present and Future, PublicAffairs, New York, 2009.

[13] DRUCKER, Johanna, The Virtual Codex from Page Space to E-space, 2003, http://www.philobiblon.com/drucker/

[14] FEBVRE, Lucian; MARTIN, Henri-Jean, The Coming of the Book - The Impact of Printing 1450 1800. Verso, second ed. London, 1997.

[15] FINKELSTEIN, David; McCLEERY, Alistair, An Introduction to Book History. Routledge, New York, 2005.

[16] FINKELSTEIN, David; McCLEERY, Alistair, The Book History Reader. second ed. Routledge, New York, 2006.

[17] FURTADO, José Afonso, O Livro, Difusão Cultural, Lisboa, 1995.

[18] FURTADO, José Afonso, Livro e leitura no novo ambiente digital. 2002. http://www.educ.fc.ul.pt/hyper/resources/afurtado/index.htm

[19] FURTADO, José Afonso, O Papel e o Pixel: Do impresso ao digital: continuidades e transformações, Ariadne, Lisboa, 2007.

[20] FURTADO, José Afonso, A Edição de Livros e a Gestão Estratégia, second ed. Booktailers, Lisboa, 2009.

[21] HAYLES, N. Katherine, Electronic Literature: New Horizons for the Literary, University of Notre Dame Press, 2008.

[22] HASLAM, Andrew, Book Design, Laurence King, London, 2006.

[23] JISC, National E-Books Observatory Project: Key findings and recommendations. Final Report, 2009. www.jisc-collections.ac.uk

[24] MEADOWS, Chris, Are programmers 'ruining' e-books?, 2012, http://www.teleread.com/ebooks/areprogrammers-ruining-e-books/

[25] MOD, Craig, Books in the Age of the iPad, 2010, http://craigmod.com/journal/ipad_and_books/\#starts_content

[26] MOD, Craig, Post-Artifacts Books \& Publishing, 2011, http://craigmod.com/journal/post_artifact/\#section_5

[27] MUNARI, Bruno, Das Coisas Nascem Coisas, Edições 70, Lisboa, 2008.

[28] PATINO, Bruno, Rapport sur le livre numérique, 2008, http://www.culture.gouv.fr/culture/actualites/conferen/albanel/rapportpatino.pdf

[29] THOMPSON, John B, Books in the Digital Age, Polity Press, Malden, 2008. 